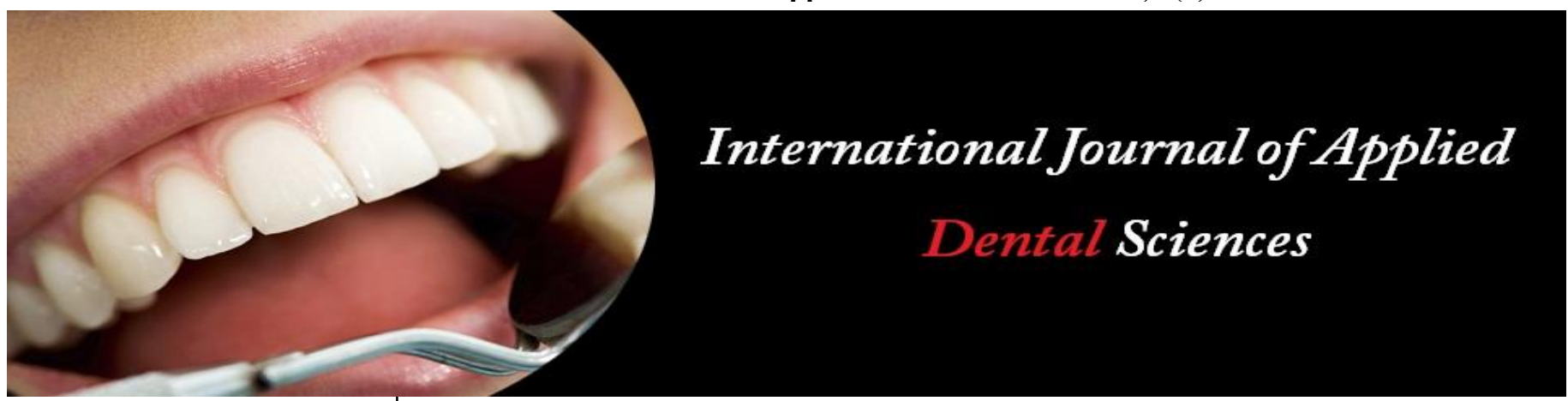

ISSN Print: 2394-7489

ISSN Online: 2394-7497

IJADS 2020; 6(4): 292-295

(C) 2020 IJADS

www.oraljournal.com

Received: 08-09-2020

Accepted: 12-10-2020

Marwah Albarshah

Post Graduate Student,

Department of Pediatric,

Dentistry, Faculty of Dentistry,

Hama University, Hama, Syria

Mohamad Hamdan

Post Graduate Student,

Department of Pediatric

Dentistry, Faculty of Dentistry,

Hama University, Hama, Syria

Khaled M Kabbesh

Teacher in Al-Wataniya Private

University-Faculty of Dental

medicine, Hama, Syria
Corresponding Author:

Marwah Albarshah

Post Graduate Student,

Department of Pediatric,

Dentistry, Faculty of Dentistry,

Hama University, Hama, Syria

\section{Comparison of quality of obturation and instrumentation time using different in primary molars}

\section{Marwah Albarshah, Mohamad Hamdan and Khaled M Kabbesh}

DOI: $\underline{\text { https://doi.org/10.22271/oral.2020.v6.i4e.1079 }}$

\section{Abstract}

Cleaning and shaping plays a very important role in success of root canal procedures. There are various instrumentation techniques available for root canal preparation. Recently, an exclusive rotary file for root canal preparation of primary teeth has been introduced.

Materials and Methods: Forty- five primary mandibular molars were randomly allotted to one of the three groups. Instrumentation was done using $\mathrm{K}$ - files in Group 1; Protaper in Group 2; and Mtwo in Group 3. Instrumentation time was recorded. The canal filling quality was assessed as underfill, optimal fill, and overfill. Statistical analysis was done using Chi- square, ANOVA, and post hoc Tukey test.

Results: No significant difference was observed in the quality of obturation among three groups. Intergroup comparison of the instrumentation time showed a statistically significant difference between the three groups.

Conclusion: The use of rotary instrumentation in primary teeth results in marked reduction in the instrumentation time and improves the quality of obturation.

Keywords: Primary teeth, pulpectomy, randomized controlled trial, rotary instrumentation

\section{Introduction}

Successful pulp therapy (SPT) requires absolute aseptic condition of the root canals by adequately cleaning and shaping the root canal ${ }^{[1]}$. Convoluted pulpal canals often make the biomechanical preparation a challenging process in primary teeth ${ }^{[2]}$. Ideal obturation should provide fluid impervious seal for successful pulp therapy ${ }^{[3]}$. There are numerous factors which are responsible for achieving the ideal quality of obturation such as adequate filling of the obturating material till the apex and the presence of three- dimensional seal ${ }^{[4]}$. One of the main complications faced by children following pulp therapy is the presence of postoperative pain which in turn may affect the child's behavior and quality of life ${ }^{[5]}$. Postoperative pain is due to the apical extrusion of the debris during instrumentation producing inflammatory reaction ${ }^{[6]}$. The use of hand instruments is very time consuming and produces unwanted complications like apical transportation and ledge formation [7]. Adequately tapered preparations are required to seal the root canals till the apex with the obturating material ${ }^{[8]}$. Use of rotary instrumentation for pulpectomy is anemerging practice in pediatric dentistry. The canals of the permanent teeth are prepared rapidly anduniformly with NiTi files resulting in superior obturation ${ }^{[9,10]}$. Rotary instrumentation in primary teeth was advocated for its ability to provide conical- shaped canals and reduced the instrumentation time ${ }^{[11,12,13]}$. An in vitro study comparing the canal cleaning capacity of hand files, Mtwo and ProTaper showed no significant differences ${ }^{[14]}$. Another in vitro study compared the cleaning capacity and instrumentation time of $\mathrm{K}$ - files and Mtwo and concluded that there was no significant difference in cleaning capacity, but reduced instrumentation time with the use of

Mtwo rotary system was evident ${ }^{[15]}$. There are no in vivo studies in the literature comparing the manual instrumentation with Mtwo rotary system for pulpectomy in primary teeth. Hence, the aim of this study was to comparatively evaluate the quality of obturation and instrumentation time using hand files, Protaper, and Mtwo rotary systems in primary molars. 


\section{Materials and Methods}

The randomized controlled trial was carried out in the Department of Pediatric dentistry, Hama, Syria. The informed consent was obtained from the parents of the children participated in the study. A total of 45 children aged 4-8 years requiring pulpectomy in any one of the primary mandibular molars were randomly allotted to one of the three groups where instrumentation was done using: Group 1: manual Kfiles; Group 2: pro Taper rotary system; Group 3: Mtwo rotary system. Computer- generated randomization sequence was generated by a person, not involved in the study. The sample size was calculated from a previous in vivo study with 95\% power using G Power analysis ${ }^{[16]}$. The selection of the children was based on the following criteria: (a) vital or nonvital mandibular primary molars without sinus tract, absence of internal or external pathologic root resorption, (c) presence of adequate coronal tooth structure to receive SS crown. The children lacking cooperative ability, children with underlying systemic diseases, and children with special health-care needs were excluded from the study. All the procedures were done by a single operator.

A full mouth examination with intraoral periapical radio graphs of the teeth indicated for pulpectomy was taken before the start of the clinical procedure. After confirmation of the diagnosis, local anesthesia was administrated using $2 \%$ lignocaine with1:200,000 adrenaline (LOX* $2 \%$ ADRENALINE, Neon Laboratories limited, India). The tooth was isolated using rubber dam (GDC Marketing, India). Using a round carbide bur in a high-speed hand piece, the superficial caries and roof of the pulp chamber were removed. Coronal pulp amputation was done with spoon excavator. No. 10 size K-file was used to determine the patency of the canals. The working length was determined with radiograph and was kept1 $\mathrm{mm}$ short of the apex. The canal preparation was done using:

- Group 1: K-files from size 15 to size 30 in quarter pull turn method.

- Group 2: Only S2 ProTaper file was used till the working length using an $\mathrm{X}$ - Smart motor. (Dentsply India Pvt. Ltd., Delhi, India)

- Group 3: Only Mtwo file of 0.04 taper and 0.25tip with $\mathrm{X}$-Smart motor till the full working length (Dentsply India Pvt. Ltd., Delhi, India).

During the canal preparation, the instrumentation time was recorded in seconds using a stopwatch byan assistant. The canals were then irrigated with saline and dried using sterile paper points.

The obturation was done using calcium hydroxide and iodoform paste by gently pushing with cotton pellets (Metapex, Meta Biomed Co., Ltd., Korea). A post obturation radiograph was taken to assess the quality of obturation. It assessed by another pediatric dentist who was blinded to the type of instrumentation used for canal preparation. The obturation quality was graded as under fill, optimal fill, overfill. The glass ionomer cement (Shofu, Shofuinc. Japan) was given as the entrance filling. The pulpectomy treated teeth were restored with SS crowns either on the same day or in the next appointment. The statistical analysis was done using SPSS software version 17.0. (Chicago, SPSS Inc). Chisquare test was used for inter-and intra-group analysis of quality of obturation. ANOVA and post hoc Tukey test were used for the compare the instrumentation time.

\section{Results \& Discussion}

\section{Results}

A total of 23 girls and 22 boys were participated in the study. The distribution of the participants is tabulated [Table 1].

Table 1: Distribution of the participants

\begin{tabular}{|c|c|c|c|c|}
\hline & $\mathbf{N}$ & Mean age & Female (\%) & Male (\%) \\
\hline K-file & 15 & $5.60+\_1.121$ & 53.3 & 46.7 \\
\hline ProTaper & 15 & $5.60+\_1.183$ & 40 & 60 \\
\hline Mtwo & 15 & $5.46+\_1.506$ & 60 & 40 \\
\hline Total & 45 & $5.56+\_1.253$ & 51.1 & 48.9 \\
\hline
\end{tabular}

Of 45 treated primary mandibular molars, $24.4 \%$ and $17.8 \%$ were mandibular left primary second and first molars, respectively. Mandibular right first and second molars comprised $28.9 \%$ each. An intergroup comparison was done with respect to the age, gender, and distribution of the teeth using ANOVA and Chi-square test. No statistically significant difference was noted between the groups with respect to the age $(P=0.947)$, gender $(P=0.537)$, and distribution of teeth $(P=0.704)$ indicating that there was an equal distribution of the participants and the teeth between all the three groups. With respect to quality of obturation among the groups, in Group 1 (K- files): $60 \%$ of the mesial canals were optimally filled; $13.3 \%$ and $26.7 \%$ were under- and Over-filled, respectively. In the distal canals, $40 \%$ were optimally filled, $26.7 \%$ were underfilled, and $33.3 \%$ were overfilled. In Group 2 (Protaper): $73.3 \%$ of the mesial canals were optimally filled; $13.3 \%$ were under- and over-filled each. $60 \%$ of the distal canals were optimally filled; $20 \%$ were under- and over-filled each. In Group 3 (Mtwo): $60 \%$ of the mesial canals were optimally filled; $33.3 \%$ were under- filled and $6.7 \%$ was overfilled. In the distal canals, $53.3 \%$ were optimally filled; $26.7 \%$ were underfilled, and $20 \%$ were overfilled. Inter- and intragroup comparison of quality of obturation was done using Chi-square test. No statistically significant difference was observed in mesial $(P=0.370)$ and distal canals $(P=0.823)$ between the three groups [Table 2].

Table 2: Intergroup analysis of quality of obturation

\begin{tabular}{|c|c|}
\hline & P \\
\hline Mesial canal & $0.370(\mathrm{NS})$ \\
\hline Distal canal & $0.823(\mathrm{NS})$ \\
\hline
\end{tabular}

$P<0.05$, significant. NS: Not significant

Between the mesial and distal canals, there was no significant difference in the teeth instrumented with $\mathrm{K}$-file $(P=0.218)$.A significant difference was noticed between the mesial and the distal canals of the teeth instrumented with ProTaper $(P=$ $0.036)$ and Mtwo $(P=0.002)$. The quality of obturation was superior in mesial canals than the distal canals [Table 3].

Table 3: Intragroup analysis of the quality of obturation between mesial and distal canals

\begin{tabular}{|c|c|}
\hline Value & P \\
\hline K-file & 0.216 \\
\hline ProTaper & 0.036 \\
\hline Mtwo & 0.002 \\
\hline
\end{tabular}

The mean instrumentation time is depicted in Table 4. Intergroup comparison was done using ANOVA and a statistically significant difference was noted between the three groups $(P=0.000)$ [Table 4$]$. 
Table 4: Instrumentation time of the three groups

\begin{tabular}{|c|c|c|c|}
\hline Instrumentation time & $\mathbf{N}$ & Mean+-SD & ANOVA \\
\hline K-file & 15 & $95.47+-12.716$ & $\mathrm{P}=0.000$, significant \\
\hline ProTaper & 15 & $45.93+-10.074$ & \\
\hline Mtwo & 15 & $54.73+-13.139$ & \\
\hline Total & 45 & $65.38+-24.796$ & \\
\hline
\end{tabular}

SD: Standard deviation

Post hoc Tukey analysis confirmed that there was a significant reduced instrumentation time between the rotary and manual instrumentation [Table 5].

Table 5: Post hoc test

\begin{tabular}{|c|c|c|}
\hline Group(I) & Group(J) & Significant \\
\hline \multirow{2}{*}{ K-file } & ProTaper & 0.000 \\
\cline { 2 - 3 } & Mtwo & 0.000 \\
\hline \multirow{2}{*}{ ProTaper } & K-file & 0.000 \\
\cline { 2 - 3 } & Mtwo & 0.125 \\
\hline \multirow{2}{*}{ Mtwo } & K-file & 0.000 \\
\cline { 2 - 3 } & ProTaper & 0.125 \\
\hline
\end{tabular}

$P<0.05$, significant

\section{Discussion}

Early loss of primary molars is a serious issue of concern in pediatric dentistry. Pulpectomy should be the treatment option to maintain the integrity of facial tissue. Cleaning and shaping of the root canal is an important step in pulpectomy. The success of an endodontic procedure depends on the proper mechanical debridement and obturation quality ${ }^{[17]}$. There are many in vitro studies done in primary teeth comparing different rotary instrumentation systems with manual instrumentation ${ }^{[11,18,13]}$. As there are no in vivo study done comparing manual files with ProTaper and Mtwo, this randomized, controlled, single-blinded trial was conducted to evaluate the quality of obturation and instrumentation time using K-file, ProTaper, and Mtwo. ProTaper files are triangular in cross-section while the Mtwo files have S-shaped cross section. These files get engaged into the walls of the canals, producing smooth and tapered canal walls [19, 20]. Nagaratna et al. reported that the increased risk of instrument fracture with rotary instruments is a potential limitation for its use in primary teeth ${ }^{[21]}$. This is due to the softer and less denser root dentin, thinner and more curved roots with undetectable root tip resorption, and ribbon- shaped root morphology of the primary teeth ${ }^{[22]}$. There are no clear guidelines for the sequence of using rotary files in primary teeth. Hence, a modified sequence of using only S2 file in ProTaper system and $0.04 \%$ taper with 0.25 tip of Mtwo rotary file was selected in this current study. This modified sequence combined with its use in a torque-limited handpiece resulted in no instrument separation within the canals. With regard to the quality of obturation, there was no statistically significant difference between the groups in both mesial and distal canals. In the study done by Abbas Makarem in 2014 and Tania Ochoa-Romero in 2011, a statistically significant difference was noted in the quality of obturation [23, 24]. Intragroup comparison showed superior obturation of the mesial canals in both rotary groups. The distal canals instrumented with rotary files were over obturated in majority of the cases. This could be due to the anatomy of the root canals. Distal canals are usually straight and wide while the mesial canals are curved and slender. In the current study, a significant difference in the instrumentation time was noted between the three groups. The reduced instrumentation time was also evident in other studies done with different rotary systems ${ }^{[16,23]}$. This decrease in the instrumentation time could positively influence the behavior of the child in the dental chair. Inclusion of only the mandibular molars is considered as the potential confounder in the current study.

\section{Conclusions}

With the use of rotary instruments for pulpectomy in primary teeth, marked reduction in the instrumentation time has been appreciated resulting in decreased chair side time thereby positively influencing the child's behavior.

\section{References}

1. Muliyar S, Shameem KA, Thankachan RP, Francis PG, Jayapalan CS, Hafiz KAA. Microleakage in Endodontics. J Int Oral Health 2014;6:99-104.

2. Ansari I, Maria R. Managing curved canals. Contemp Clin Dent 2012;3:237-41.

3. Schilder H. Vertical compaction of warm gutta-percha. In: Gerstein $\mathrm{H}$, editor. Techniques in Clinical Endodontics. Philadelphia, PA: WB Saunders 1983, 7698.

4. Schilder H. Cleaning and shaping the root canal. Dent Clin North Am 1974;18:269-96.

5. Low W, Tan S, Schwartz S. The effect of severe caries on the quality of life in young children. Pediatr Dent 1999;21:325-6.

6. Borges ÁH, Pereira TM, Porto AN, de Araújo Estrela CR, Miranda Pedro FL, Aranha AM et al. The influence of cervical preflaring on the amount of apically extruded debris after root canal preparation using different instrumentation systems. J Endod 2016;42:465-9.

7. Uelzow A, Stamm O, Martus P, Kielbassa AM. Comparative study of six rotary nickel-titanium systems and hand instrumentation for root canal preparation Int Endod J 2005;38:743-52.

8. Chugal NM, Clive JM, Spångberg LSW. Endodontic infection: Some biologic and treatment factors associated with outcome. Oral Surg Oral Med Oral Pathol Oral Radiol Endod 2003;96:81-90.

9. Deplazes P, Peters O, Barbakow F. Comparing apical preparations of root canals shaped by nickel-titanium rotary instruments and nickel- titanium hand instruments. J Endod 2001;27:196-202.

10. Barbizam JV, Fariniuk LF, Marchesan MA, Pecora JD, Sousa- Neto MD. Effectiveness of manual and rotary instrumentation techniques for cleaning flattened root canals. J Endod 2002;28:365-6.

11. Silva LA, Leonardo MR, Nelson- Filho P, Tanomaru JM. Comparison of rotary and manual instrumentation techniques on cleaning capacity and instrumentation time in deciduous molars. J Dent Child (Chic) 2004;71:45-7.

12. Pinheiro SL, Araujo G, Bincelli I, Cunha R, Bueno C. Evaluation of cleaning capacity and instrumentation time of manual, hybrid and rotary instrumentation techniques in primary molars. Int Endod J 2012;45:379- 85.

13. Kuo C, Wang Y, Chang H, Huang G, Lin C, Li U, et al. Application of $\mathrm{Ni}^{-} \mathrm{Ti}$ rotary files for pulpectomy in primary molars. J Dent Sci 2006;1:10- 5.

14. Azar MR, Safi L, Nikaein A. Comparison of the cleaning capacity of Mtwo and Pro Taper rotary systems and manual instruments in primary teeth. Dent Res J (Isfahan) 2012;9:146- 51.

15. Ramezanali F, Afkhami F, Soleimani A, Kharrazifard MJ, Rafiee F. Comparison of cleaning efficacy and instrumentation time in primary molars: Mtwo rotary 
instruments vs. hand $\mathrm{K}^{-}$files. Iran Endod $\mathrm{J}$ 2015;10:240- 3.

16. Vieyra JP, Enriquez FJ. Instrumentation time efficiency of rotary and hand instrumentation performed on vital and necrotic human primary teeth: A Randomized Clinical Trial. Dentistry 2014;4:1 - 5.

17. Tabassum S, Khan FR. Failure of endodontic treatment: The usual suspects. Eur J Dent 2016;10:144- 7.

18. Barr ES, Kleier DJ, Barr NV. Use of nickel-titanium rotary files for root canal preparation in primary teeth. Pediatr Dent 2000;22:77- 8.

19. Foschi F, Nucci C, Montebugnoli L, Marchionni S, Breschi L, Malagnino VA, et al. SEM evaluation of canal wall dentine following use of Mtwo and ProTaperNiTi rotary instruments. Int Endod J 2004;37:832- 9.

20. Malagino VA, Grande NM, Plotino G, Somma F. The MtwoNiTi Rotary System for Root Canal Preparation. Available from: http://www.vdw- dental.com/pdf/presse/RO0306_59-62 _Malagino.pdf. [Cited on 2012 Apr 04].

21. Nagaratna PJ, Shashikiran ND, Subbareddy VV. In vitro comparison of NiTi rotary instruments and stainless steel hand instruments in root canal preparations of primary and permanent molar. J Indian Soc PedodPrev Dent 2006;24:186- 91.

22. Finn SB, editor. Morphology of primary teeth. In: Clinical Pedodontics. 4th ed. Philadelphia: Saunders Co 1973, 59- 70.

23. Makarem A, Ravandeh N, Ebrahimi M. Radiographic assessment and chair time of rotary instruments in the pulpectomy of primary second molar teeth: A randomized controlled clinical trial. J Dent Res Dent Clin Dent Prospects 2014;8:84- 9.

24. Ochoa-Romero T, Mendez-Gonzalez V, Flores-Reyes H, Pozos-Guillen AJ. Comparison between rotary and manual techniques on duration of instrumentation and obturation times in primary teeth. J Clin Pediatr Dent 2011;35:359- 63 . 